EPiC Series in Engineering
Volume 3, 2018, Pages 1155-1161
HIC 2018. 13th International
Conference on Hydroinformatics

\title{
Hydrological model calibration in data-limited catchments using non-continuous data series with different lengths
}

\author{
Chuanzhe $\mathrm{Li}^{1 *}$, Jia Liu ${ }^{1}$, Fuliang $\mathrm{Yu}^{1}$, Jiyang Tian ${ }^{1}$, Yang Wang ${ }^{1}$ and \\ Qingtai Qiu ${ }^{1}$ \\ ${ }^{1}$ State Key Laboratory of Simulation and Regulation of Water Cycle in River Basin, China \\ Institute of Water Resources and Hydropower Research, Beijing, China \\ azhe051@163.com, hettyliu@126.com, yufl@iwhr.com, tjyshd@126.com, \\ ywwangyang@163.com, qqt31415926@163.com
}

\begin{abstract}
This paper evaluates the effects of calibration data series length on the performance of a hydrological model in data-limited catchments where data are non-continuous and fragmental. Non-continuous calibration periods were used for more independent streamflow data for SIMHYD model calibration. Nash-Sutcliffe efficiency and percentage water balance error were used as performance measures. The particle swarm optimization method was used to calibrate the rainfall-runoff models. Different lengths of data series ranging from one year to ten years were used to study the impact of calibration data series length. Fifty-five relatively unimpaired catchments located all over Australia with daily precipitation, potential evapotranspiration, and streamflow data were tested to obtain more general conclusions. The results show that longer calibration data series do not necessarily result in better model performance. Our results may have useful and interesting implications for the efficiency of using limited observation data for hydrological model calibration in different climates.
\end{abstract}

\section{Introduction}

How long of a data series should be used for hydrological model calibration? This is an especially important question when model users are applying models in data-limited catchments (Boughton, 2007). It is important to make the best use of these limited data. In general, model users tend to use the longest available data series for model calibration in order to achieve more representative calibration. However, it is not the length of the data series used but the information contained in it and

\footnotetext{
${ }^{*}$ Corresponding author
} 
the efficiency with which that information is extracted that are important (Sorooshian, Gupta, \& Fulton, 1983). Many researchers have concluded that longer calibration data series do not necessarily result in better model performance. They have recommended different lengths of data series ranging from three months to ten years for calibration according to different models and study regions (Yapo, Gupta, \& Sorooshian, 1996; Gan, Dlamini, \& Biftu, 1997; Perrin, Oudin, Andreassian, Rojas-Serna, Michel, 2007). One full hydrological year is suggested for CRR model calibration as a minimum data requirement (Sorooshian, Gupta, \& Fulton, 1983). It should be noted that most researchers use continuous calibration data for model calibration. There are few reports in the literature that have considered both non-continuous calibration periods and data for a full hydrological year in hydrological model calibration.

The main objective of this study was to demonstrate the importance of calibration data length to the estimates of optimal parameters and uncertainty performance of the conceptual rainfall-runoff models. This study can help improve application of hydrological model in data-limited catchments. We used non-continuous calibration periods in order to have more independent runoff data for model calibration. Different lengths of data series ranging from one year to ten years, randomly sampled, were used to study the impact of calibration data length. Fifty-five relatively unimpaired catchments located all over Australia were tested to obtain more general conclusions.

\section{Hydrological Model and Data}

\subsection{SIMHYD Model}

SIMHYD is a lumped conceptual daily rainfall-runoff model. It is driven by daily rainfall and potential evapotranspiration, and simulates daily streamflow. It has been tested and used extensively across Australia (Siriwardena, Finlayson, \& McMahon, 2006; Zhang, Chiew, Zhang, Leuning, \& Cleugh, 2008). Figure 1 shows the structure of SIMHYD as well as the algorithms. The version of the SIMHYD model used in this study has nine parameters. The ranges of these parameters are shown in Table 1.

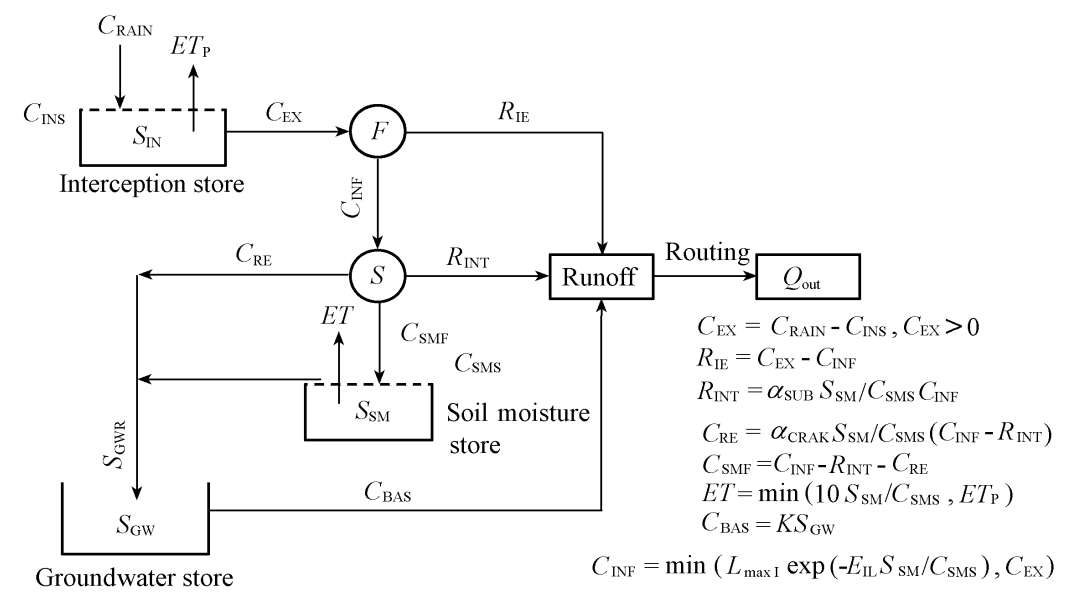

Figure 1: Structure of lumped rainfall-runoff model SIMHYD 


\begin{tabular}{lrrr}
\hline Parameter & Description & $\begin{array}{r}\text { Minimum } \\
\text { value }\end{array}$ & $\begin{array}{r}\text { Maximum } \\
\text { value }\end{array}$ \\
\hline$C_{\mathrm{INS}}$ & Interception store capacity (mm) & 0.5 & 5.0 \\
$L_{\mathrm{Maxl}}$ & Maximum infiltration loss (mm) & 50 & 400 \\
$E_{\mathrm{IL}}$ & Infiltration loss exponent & 0 & 6.0 \\
$C_{\mathrm{SMS}}$ & Soil moisture store capacity (mm) & 50 & 500 \\
$\alpha_{\mathrm{SUB}}$ & Constant of proportionality in interflow equation & 0 & 1 \\
$\alpha_{\mathrm{CRAK}}$ & Constant of proportionality in groundwater recharge & 0 & 1 \\
& equation & 0.003 & 0.3 \\
$K$ & Baseflow linear recession parameter & 0 & 0.5 \\
$E_{\mathrm{X}}$ & Proportionality constant of Muskingum routing \\
& method & 0.5 & 10 \\
$E_{\mathrm{K}}$ & Storage-time constant of Muskingum routing method & & \\
\hline
\end{tabular}

Table 1: Description and ranges of parameters in SIMHYD model

\subsection{Study Catchment and Data}

Daily streamflow data from 55 unimpaired catchments located all over Australia were used in this study (Figure 2). Unimpaired streamflow is defined as streamflow that is not subject to regulation or diversion. The data are a subset of the Australian dataset collated for an Australian Land and Water Resources Audit project (Peel, Chiew, Western, \& McMahon, 2000). The spatial resolution of the gridded daily rainfall was $5 \mathrm{~km}$ by $5 \mathrm{~km}$ based on interpolation of over 6000 rainfall stations in Australia. The catchments range in area from $51 \mathrm{~km}^{2}$ to $1891 \mathrm{~km}^{2}$. The mean annual rainfall in the catchments ranges from $587 \mathrm{~mm}$ to $2886 \mathrm{~mm}$, and the mean annual runoff ranges from $44 \mathrm{~mm}$ to $2095 \mathrm{~mm}$. The runoff coefficients of the catchments range from 0.08 to 0.89 , and the index of dryness ranges from 0.37 to 2.19 , representing diverse hydrological and climatic conditions.

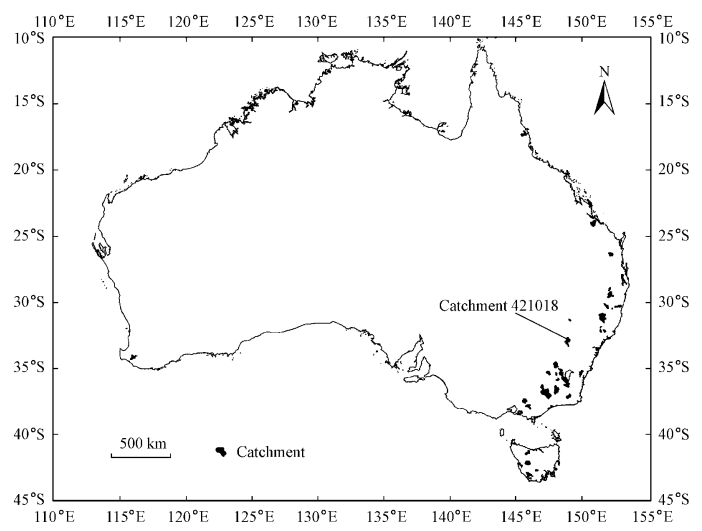

Figure 2: Location of 55 catchments in Australia used for this study

\section{Methodology}

We designed different lengths of data series available to calibrate the SIMHYD model. Calibration runs were conducted using data lengths of one, two, three, five, eight, and ten non-continuous years randomly selected from the whole observation data set. We sampled 100 times randomly, with lengths 
of two, three, five, eight, and ten years. When the data series length was one year, data from every year were sampled independently from the whole observation data set. Calibration data assembled in non-continuous years including different climatic conditions were sufficient to obtain robust estimates of model performance and parameters. This method is more suitable for catchments where data are limited and fragmentary. The performance of each calibration was evaluated for the whole period, using Nash-Sutcliffe efficiency $\left(E_{\mathrm{NS}}\right)$ and water balance error percentage $\left(E_{\mathrm{WB}}\right)$ defined below. The particle swarm optimization (PSO) (Eberhart \& Kennedy, 1995) was used to optimize the parameters of the rainfall-runoff model.

$$
E_{\mathrm{NS}}=1-\frac{\sum_{i=1}^{N}\left(Q_{\mathrm{obs}, i}-Q_{\mathrm{sim}, i}\right)^{2}}{\sum_{i=1}^{N}\left(Q_{\mathrm{obs}, i}-\bar{Q}_{\mathrm{obs}}\right)^{2}}
$$

where $Q_{\mathrm{sim}, i}$ and $Q_{\mathrm{obs}, i}$ are the simulated daily runoff and observed daily runoff, respectively; $\bar{Q}_{\mathrm{obs}}$ is the arithmetic mean of the observed runoff; $i$ represents the $i$ th day; and $N$ is the total days sampled.

$$
E_{\mathrm{wB}}=\frac{\sum_{i=1}^{N}\left(Q_{\mathrm{sim}, i}-Q_{\mathrm{obs}, i}\right)}{\sum_{i=1}^{N} Q_{\mathrm{obs}, i}} \times 100
$$

For the optimization, the two criteria are aggregated into one objective function $f_{\text {obj }}$ :

$$
f_{\text {obj }}=\alpha\left(1-E_{\mathrm{NS}}\right)+\beta\left|E_{\mathrm{WB}}\right|
$$

The weighting factors of $\alpha$ and $\beta$ are set at 1 and 0.01 , respectively.

\section{Results and Discussion}

\subsection{Model Calibration and Verification Results}

The calibrated and verified results of the SIMHYD model ( $E_{\mathrm{NS}}$ and absolute $E_{\mathrm{WB}}$ ) using different calibration data series lengths for 55 catchments are shown in Figure and Figure 4, in which T1, T2, T3, T5, T8, and T10 represent the data series lengths of one, two, three, five, eight, and ten years, respectively. The standard deviations of $E_{\mathrm{NS}}$ and absolute $E_{\mathrm{wB}}$ values for different calibration data series lengths are shown in Figure 5 and Figure 6, respectively for the calibration and verification results.

It can be seen in Figure 3 that the curves of $E_{\mathrm{NS}}$ are closer together and become steeper as we progress from the one-year to the ten-year data sets. The steeper the curves of $E_{\mathrm{NS}}$ are, the greater the sensitivity of model performance to selection of the calibration data set. The shift of the distribution indicates improvement of model performance with shorter data sets. In Figure 3(b), the curves of absolute $E_{\mathrm{WB}}$ steepen progressively with increasing data series length. From eight years on, the curves of absolute $E_{\mathrm{WB}}$ show little or no change as data series length increases, indicating no improvement in the distribution of absolute $E_{\mathrm{wB}}$. The standard deviations of $E_{\mathrm{NS}}$ and absolute $E_{\mathrm{wB}}$ values show similar results in Figure 4. The curves steepen with increasing data series length. From eight years on, the changes lessen. This indicates that the SIMHYD model can generate more stable $E_{\mathrm{NS}}$ and absolute $E_{\mathrm{wB}}$ values with short calibration data series over different catchments. 
For the verification results in Figure 5, both the trends of $E_{\mathrm{NS}}$ and absolute $E_{\mathrm{WB}}$ indicate that the verification performance tends to improve when the number of years used for calibration increases. When the length of calibration is longer than eight years, it can be inferred that the model performance reaches steady and satisfactory results with high $E_{\mathrm{NS}}$ values and low absolute $E_{\mathrm{WB}}$ values. The standard deviation values of $E_{\mathrm{NS}}$ and absolute $E_{\mathrm{WB}}$ in Figure 6 show a similar tendency. It is clear that longer calibration data series may provide more consistent and better calibration and verification values, and result in more consistent simulations. However, due to the huge cost of measurement and collection of calibration and forcing data, short calibration data sets have often been used. Our results indicate that eight-year data sets may be adequate for SIMHYD, achieving the optimal calibration and verification values.
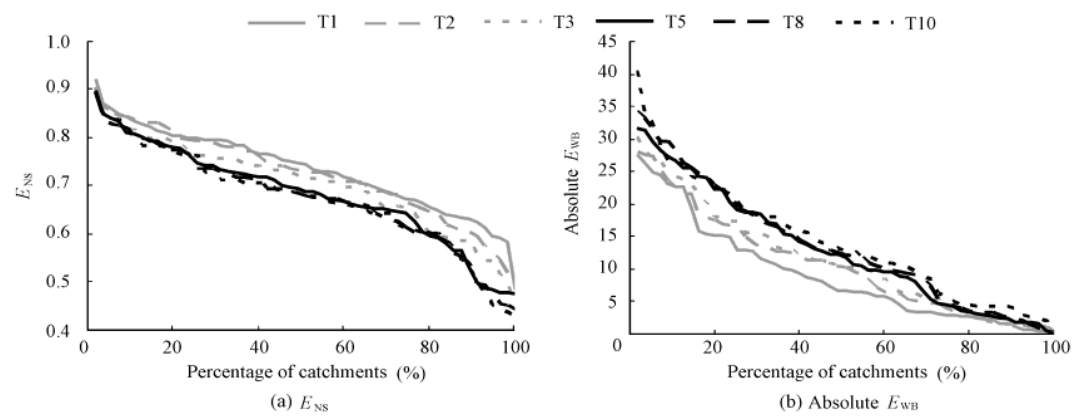

Figure 3: Summary of calibrated $E_{\mathrm{NS}}$ and absolute $E_{\mathrm{WB}}$ values for different calibration data series lengths
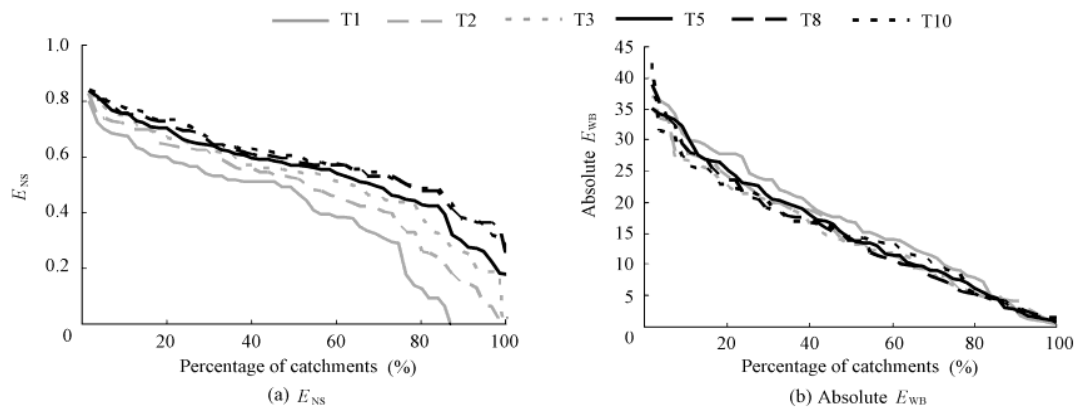

Figure 4: Summary of verified $E_{\mathrm{NS}}$ and absolute $E_{\mathrm{wB}}$ values for different calibration data series lengths
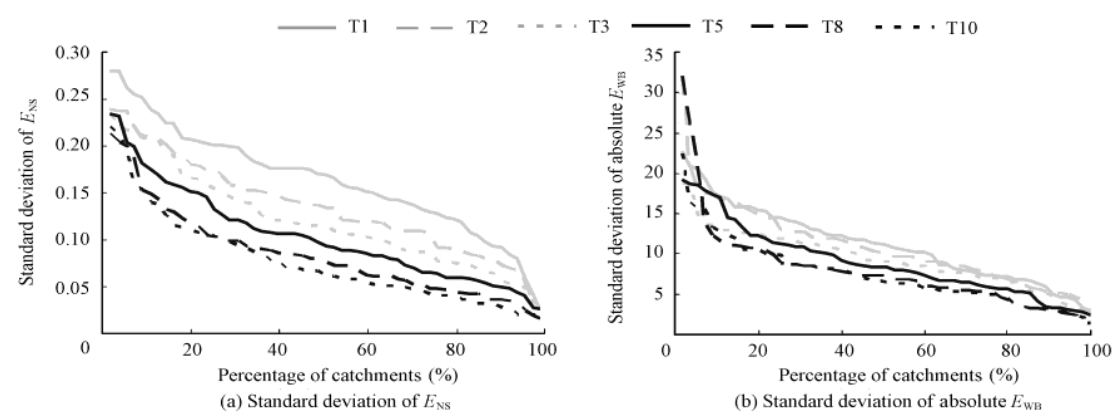

Figure 5: Standard deviation of calibrated $E_{\mathrm{NS}}$ and absolute $E_{\mathrm{WB}}$ values for different calibration data lengths 

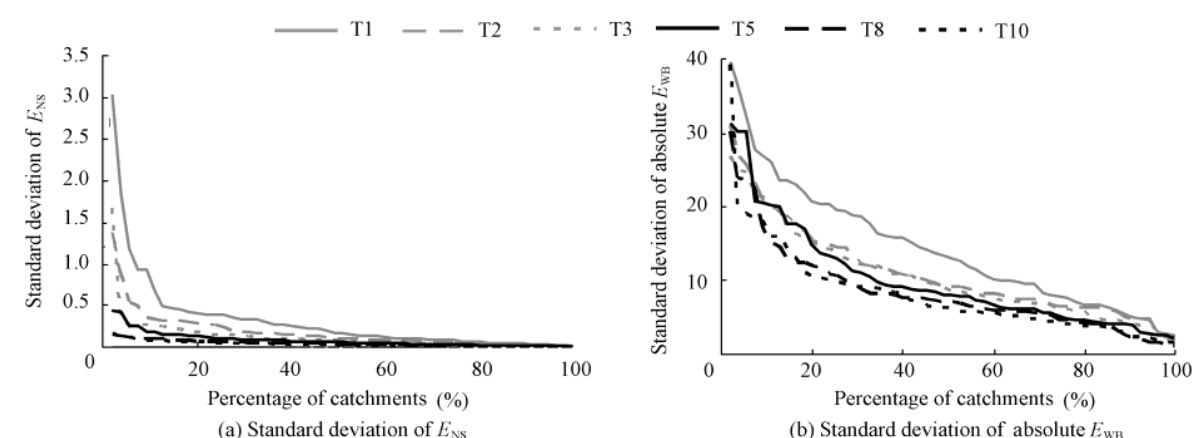

Figure 6: Standard deviation of verified $E_{\mathrm{NS}}$ and absolute $E_{\mathrm{WB}}$ values for different calibration data lengths

\subsection{Variability of the Model Parameters}

The standard deviations of parameters of catchment 421018 (shown in Figure 2) obtained with different lengths of calibration data series are compared in Table 2. Different behaviours can be observed and some parameter values become stable more quickly than others when the length of calibration year increases. Standard deviations of parameters $C_{\mathrm{INS}}$ and $L_{\mathrm{MaxI}}$ increase significantly with the increase of the length of calibration data series. Standard deviations of parameters $E_{\mathrm{IL}}, C_{\mathrm{SMS}}, \alpha_{\mathrm{SUB}}$, and $E_{\mathrm{K}}$ decrease significantly with the length of calibration data series. Standard deviations of parameters $\alpha_{\mathrm{CRAK}}, K$, and $E_{\mathrm{X}}$ show little or almost no change with increases in the length of the calibration data series. A decreasing standard deviation indicates that the variability of these model parameters decreases, while an increasing standard deviation indicates that the variability of these model parameters increases.

\begin{tabular}{lrrrrrrrrr}
\hline $\begin{array}{l}\text { Data } \\
\text { series }\end{array}$ & $\sigma_{1}$ & $\sigma_{2}$ & $\sigma_{3}$ & $\sigma_{4}$ & $\sigma_{5}$ & $\sigma_{6}$ & $\sigma_{7}$ & $\sigma_{8}$ & $\sigma_{9}$ \\
\hline T1 & 1.17 & 96.08 & 1.52 & 110.52 & 0.17 & 0.17 & 0.08 & 0.14 & 3.01 \\
T2 & 1.36 & 99.84 & 1.38 & 104.38 & 0.15 & 0.19 & 0.07 & 0.13 & 3.04 \\
T3 & 1.48 & 101.48 & 1.61 & 103.35 & 0.13 & 0.19 & 0.07 & 0.16 & 2.99 \\
T5 & 1.53 & 105.78 & 1.53 & 99.65 & 0.10 & 0.17 & 0.07 & 0.14 & 2.76 \\
T8 & 1.67 & 101.56 & 1.37 & 85.93 & 0.09 & 0.2 & 0.07 & 0.14 & 2.44 \\
T10 & 1.53 & 104.51 & 1.35 & 75.19 & 0.09 & 0.19 & 0.07 & 0.15 & 2.12 \\
\hline
\end{tabular}

Table 2: Standard deviations of model parameters (catchment 421018) with different calibration data lengths

Note: $\sigma_{1}, \sigma_{2}, \sigma_{3}, \sigma_{4}, \sigma_{5}, \sigma_{6}, \sigma_{7}, \sigma_{8}$ and $\sigma_{9}$ are the standard deviations of $C_{\mathrm{INS}}, L_{\mathrm{MaxI}}, E_{\mathrm{IL}}, C_{\mathrm{SMS}}, \alpha_{\mathrm{SUB}}, \alpha_{\mathrm{CRAK}}, K, E_{\mathrm{x}}$ and $E_{\mathrm{k}}$, respectively. 


\section{Conclusions}

Longer calibration data series may give more consistent optimal parameter values and result in more consistent simulations. However, due to the huge cost for measurement and collection of calibration and forcing data, or limited data for some ungauged catchments, short calibration data sets have often been used in previous rainfall-runoff modeling studies. Our results show that, in general, eight years of data chosen randomly are sufficient to obtain steady estimates of model performance and parameters for the SIMHYD model. They also show that most humid catchments require fewer calibration data (three years or five years) for good performance and stable parameter values. Our results may have useful and interesting implications for study of data-limited catchments, by indicating how many data points it is necessary to collect for the purpose of calibration.

\section{Acknowledgements}

This study was supported by the National Key Research and Development Program (Grant No. 2017YFC1502405, 2016YFA0601503), the Major Science and Technology Program for Water Pollution Control and Treatment (Grant No. 2018ZX07110001), the Hebei Province Water Scientific Research Project (Grant No. 2015-16), and the IWHR Research \& Development Support Program (Grant No. WR0145B732017).

\section{References}

Boughton, W. (2007). Effect of data length on rainfall-runoff modelling. Environmental Modelling and Software, 22, pp. 406-413.

Eberhart, R., \& Kennedy, J. (1995). A new optimizer using particle swarm theory. Proceedings of the Sixth International Symposium on Micro Machine and Human Science, pp. 39-43.

Gan, T., Dlamini, E., \& Biftu, G. (1997). Effects of model complexity and structure, data quality, and objective functions on hydrologic modelling. Journal of Hydrology, 192, pp. 81-103.

Peel, M., Chiew, F., Western, A., \& McMahon, T. (2000). Extension of unimpaired monthly stream flow data and regionalization of parameter values to estimate stream flow in ungauged catchments (Report to National Land and Water Resources Audit). Parkville: Center For Environmental Application and Hydrology, University of Melbourne.

Perrin, C., Oudin, L., Andreassian, V., Rojas-Serna, C., Michel, C., \& Mathevet, T. (2007). Impact of limited streamflow data on the efficiency and the parameters of rainfall-runoff models. Hydrological Sciences Journal, 52, pp. 131-151.

Siriwardena, L., Finlayson, B., \& McMahon, T. (2006). The impact of land use change on catchment hydrology in large catchments: The Comet River, Central Queensland, Australia. Journal of Hydrology, 326, pp. 199-214.

Sorooshian, S., Gupta, V., \& Fulton, J. (1983). Evaluation of maximum likelihood parameter estimation techniques for conceptual rainfall-runoff models: Influence of calibration data variability and length on model credibility. Water Resources Research, 19, pp. 251-259.

Yapo, P., Gupta, H., \& Sorooshian, S. (1996). Automatic calibration of conceptual rainfall-runoff models: Sensitivity to calibration data. Journal of Hydrology, 181, pp. 23-48.

Zhang, Y., Chiew, F., Zhang, L., Leuning, R., \& Cleugh, H. (2008). Estimating catchment evaporation and runoff using MODIS leaf area index and the Penman-Monteith equation. Water Resources Research, 44, pp. 2183-2188. 